\title{
Method for optimal vertical alignment of highways
}

\author{
A. B. Goktepe, A. H. Lav and S. Altun
}

This paper presents a methodology to consider vague soil parameters required for earthwork optimisation, and to develop a genetic algorithm-based constrained curve-fitting technique required for highway vertical alignment process. The weighted ground line method is an earthwork optimisation methodology based on a hypothetical reference line and taking into account three soil properties to calculate realistic cut-fill volumes, namely swelling potential, compactibility percentage, and material appropriateness percentage. In this study, fuzzy rule-based inference methodology, which utilises previous experiences that can be expressed with linguistic terms, is employed to characterise swelling/ shrinkage behaviour. In addition, material appropriateness concept is also adopted into developed optimisation methodology by a parametric algorithm using technical specifications and geotechnical data. Consequently, the genetic algorithm approach is employed for the determination of final grade line considering weighted ground elevations. The method involving an algorithm to consider the soil parameters as well as an evolutionary computation-based constrained curve-fitting technique produces outstanding geometric alignments.

\section{NOTATION}

$A(i, 2) y$ coordinate of the $i$ th node

$A(i, 1) x$ coordinate of the $i$ th node

$C_{M} \quad$ material coefficient

$C_{R} \quad$ relative compaction

$\boldsymbol{f}_{\mathrm{r}} \quad$ road friction factor

$g \quad$ algebraic difference between successive gradients

$g_{\max }$ maximum allowable gradient

$\Delta H \quad$ amount of shifting for $y=h_{\mathrm{w}}^{\prime}$

$h_{0} \quad$ height of object above roadway surface

$h_{\mathrm{d}} \quad$ height of driver's head above road surface

$h_{\mathrm{w}} \quad$ weighted ground elevation

$h_{\mathrm{w}}^{\prime} \quad$ weighted ground elevation considering material properties

$L \quad$ earthwork width

$L_{\mathrm{V}} \quad$ length of the vertical curve

$L^{\prime} \quad$ final earthwork width due to shifting

$m$ number of fill areas in the cross-section

$N \quad$ number of cut areas in cross-section

$P_{\mathrm{A}} \quad$ appropriateness percentage of cut material

$P_{\mathrm{C}} \quad$ compactibility percentage of fill material
$P_{\mathrm{S}} \quad$ swelling percentage of material after excavation

$R \quad$ error value

$S_{\mathrm{C}} \quad$ the cut area vector

$S_{\mathrm{C}}^{\prime} \quad$ cut areas for new positioning (for $y=h_{\mathrm{w}}^{\prime}$ )

$S_{C S} \quad$ triangular-shaped excess area due to cut slope

$S_{\mathrm{F}} \quad$ fill area vector

$S_{F S}$ triangular-shaped absence area due to fill slope

$S_{j} \quad$ sight distance

$\mathrm{V}$ driving speed

$v \quad$ number of cut areas for new positioning (for $y=h_{\mathrm{w}}^{\prime}$ )

$\gamma_{\mathrm{df}} \quad$ field dry unit weight

$\gamma_{\text {dmax }}$ maximum dry unit weight

$\delta \quad$ predetermined confidence level

$\Lambda$ chromosome

$\lambda$ gene

$\emptyset(x) \quad$ natural surface function

\section{INTRODUCTION}

Highway design requires the evaluation of several criteria such as design speed, design vehicle, traffic volume, maximum grade and highway alignment. Highway alignment is the determination of route location on a topographic map and can be considered in either a two-dimensional or three-dimensional manner. In the two-dimensional approach, adjustment is simplified by considering the problem domain as either horizontal or vertical. The three-dimensional approach, which is suitable for the nature of the problem, uses both horizontal and vertical planes to find the optimal route location; thus, more efficient solutions can be produced in terms of earthwork optimisation and the handling of additional design parameters. However, the three-dimensional alignment problem involves a large number of design variables, several non-linear constraint equations, and numerous solution alternatives; therefore, it is a complex optimisation problem that requires a direct searching technique, such as genetic algorithm and random search. ${ }^{1-4}$ Consequently, three-dimensional optimising techniques are computationally inefficient, take a lot of time to establish, and may not guarantee the desired solution. For this reason, in the majority of alignment processes, the horizontal alignment is first determined and then the vertical alignment is adjusted by a set of design controls. ${ }^{5-7}$

The weighted ground line method (WGLM) is a technique for both cut-fill balancing and earthwork minimisation, proposed by Goktepe and Lav, ${ }^{8}$ which gives an opportunity to the designer to set an optimum grade line with the consideration of 
relevant soil properties. The main idea of this method is to find a hypothetical centre elevation for each cross-section that balances cut-fill and minimises the total earthwork. In addition, material properties can be considered in the WGLM in order to evaluate realistic cut-fill volumes, namely to identify unacceptable cut material for use as a fill material, and the swelling/shrinkage factor. ${ }^{7}$

Considering the above-mentioned material properties, modification of the WGLM leads to more accuracy in the earthwork optimisation process, as it is possible to calculate realistic cut/fill possibilities utilising these factors. ${ }^{7}$ In addition, the determination of the swelling/shrinkage factor has a great deal of ambiguity that comes from the complex and heterogeneous behaviour of soils. In addition, our previous experience suggests that several linguistic expressions may be used to define this property. Therefore, it is necessary to design a decision support system for the determination of the swelling/shrinkage factor affecting earthwork optimisation under uncertain conditions. ${ }^{9}$

Fuzzy set theory provides a means for expressing uncertainties associated with vagueness, imprecision, and lack of information. The underlying power of fuzzy set theory is that it uses linguistic variables, rather than quantitative variables, to represent uncertain concepts. Therefore, fuzzy rule-based systems, which use fuzzy sets for the interpretation of linguistic expressions and apply fuzzy inference (approximate reasoning) to derive conclusions from fuzzy rules, are powerful tools for modelling uncertain environments. ${ }^{10}$ For this reason, fuzzy rule-based inference methodology is a good choice for dealing with the uncertainty in the determination of soil properties included in the WGLM. ${ }^{9}$ The first part of this study deals with the consideration of the swell/shrinkage factor affecting earthwork optimisation.

In the second part, an algorithm for the approximation of the material appropriateness percentage, which is also required for the WGLM, utilising technical specifications and geotechnical information, is developed. The algorithm for the material appropriateness percentage and developed fuzzy system complete the soil parameter determination procedure and produce the required inputs for the WGLM. Therefore, the calculation of weighted ground elevations (WGEs) is performed at this step.

In the final part of this study, the genetic algorithm (GA) approach is employed to establish the final grade line with respect to calculated WGEs. Therefore, the optimal vertical alignment method is developed for use with WGLM.

Analogously, the presented techniques can also be adapted to any multi-phase curve-fitting problem such as the highway alignment problem.

\section{LITERATURE REVIEW}

Basically, the best highway alignment can be determined by the solution of a constrained optimisation problem, in which constraints and objective function are non-linear. The reason of this non-linearity comes from the fact that there are complex relationships among design variables and it is not possible to characterise the problem considering the small number of design variables. As a result, the goal of any alignment model is to seek optimal model parameters (design variables) that minimise the output of a known cost function. Therefore, it is possible to define the highway alignment problem with the consideration of a constrained optimisation technique, such as dynamic programming and genetic algorithm. In the written material, there are numerous alignment optimisation studies that are focused on the twodimensional solution of the problem using either vertical or horizontal planes. In this context, several researchers ${ }^{10-14}$ have developed horizontal alignment models; although more emphasis has been given to vertical alignment models so far. ${ }^{15-25}$ The major discrepancies among the developed twodimensional models are based on the variety of optimisation techniques, namely linear programming, quadratic programming, gradient search, state parameterisation and dynamic programming.

In addition, some researchers have studied the threedimensional solution of highway alignment problem. In this regard, Turner and Miles ${ }^{26}$ have presented an alignment model that searched the shortest paths on calculated grid networks characterised by relative costs. After this initial attempt, more complex models were developed to obtain realistic solutions subject to several design constraints and non-linear geometric requirements. In this context, dynamic programming, state parameterisation, and genetic algorithm approaches were applied to find optimal route candidates in the threedimensional manner. ${ }^{1,2,19,27-29}$ In addition to the complex and comprehensive modelling abilities of these three-dimensional models, they are not practically applicable for most alignment problems and may not guarantee exact solutions every time. ${ }^{1,5}$ In the light of these, a hypothetical WGE concept, focusing on the vertical alignment, has recently been suggested to determine the optimum grades, practically for both hand and computer calculations. ${ }^{7,8}$

Apart from these, there are numerous studies focusing on other relevant factors affecting the optimality of highway alignment, such as intersection design, ${ }^{24,25}$ sight distance, ${ }^{30}$ socioeconomic and environmental aspects, ${ }^{31}$ traffic characteristics, ${ }^{32}$ and volume calculation methodology. ${ }^{33}$ It is clear that highway alignment optimisation is a quite complex and multivariate problem in nature.

As mentioned above, the WGLM was first implemented by Goktepe and Lav. ${ }^{7}$ Subsequently, soil parameters were included in the WGLM by the authors. ${ }^{8}$ Later, a fuzzy decision support system was suggested to select the swell/shrink factor in another study. ${ }^{9}$ It should be noted that the fuzzy logic-based parameter selection procedure was implemented previously, and is beyond the primary scope of this study. However, the aim of this study is to accomplish a WGLM-based alignment optimisation process and to implement a complete alignment optimisation procedure. The procedure also considers the uncertainty and heterogeneity in the soil information. The previous studies mentioned above implemented the basic approaches which constituted the major part of this system; therefore, they are considered and expressed in this paper. On the other hand, the previous study ${ }^{9}$ only deals with the definition of the parameter selecting methodology using fuzzy logic. In the present study, this philosophy is applied to the optimisation procedure efficiently. Moreover, the heterogeneity 
in a roadway section is considered in this study with an innovative approach. In this context, a procedure for the consideration of the soil appropriateness is implemented. Later, the vertical alignment process is accomplished using the genetic algorithm technique to complete the alignment optimisation problem. Finally, the methodology is tested and evaluated with a numerical example.

\section{WEIGHTED GROUND LINE METHOD}

Essentially, vertical alignment is established along the centreline of the road in highway projects; therefore, the centre ground line is considered as the reference line. In reality, however, the centre ground elevations rarely represent the topography of entire cross-section. The term weighted ground elevation (WGE) is a hypothetical centre elevation. It represents the topography of the cross-section and optimises the earthwork quantities in terms of cut-fill balance and total earthwork minimisation. The mathematical representation of WGE is given by

$$
\sum_{i=1}^{n} S_{\mathrm{C}}(i)=\sum_{i=1}^{m} S_{\mathrm{F}}(i) \quad\left(\text { for } y=h_{\mathrm{W}}\right)
$$

where $h_{\mathrm{w}}$ is the WGE, $\boldsymbol{S}_{\mathrm{C}}$ is the cut area vector, $\boldsymbol{S}_{\mathrm{F}}$ is the fill area vector, $n$ is the number of cut areas in cross-section, and $m$ is the number of fill areas in the cross-section. In Figure 1, relevant notation used for the calculation WGE is shown for a cross-section that has $p$ nodes within the earthwork width. The formulation of calculating WGE is given in the following equation

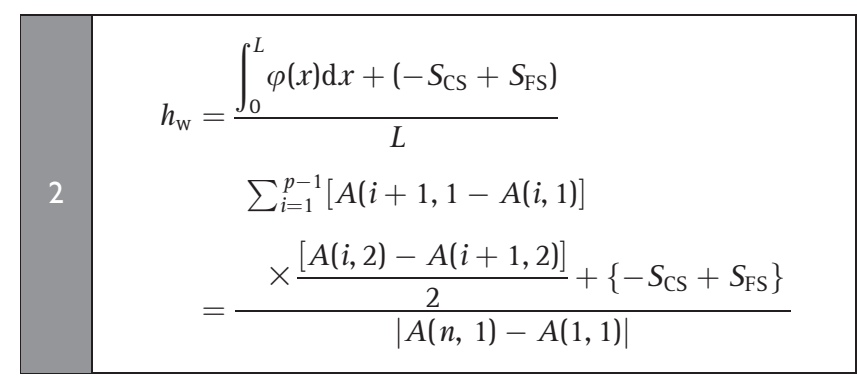

where $\varphi(x)$ is natural surface function, $L$ is earthwork width, $A(i, 2)$ is $y$-coordinate of the $i$ th node, $A(i, 1)$ is $x$-coordinate of the $i$ th node, $S_{\mathrm{CS}}$ is a triangular-shaped excess area due to cut slope, $S_{\mathrm{FS}}$ is triangular-shaped absence area due to fill slope. As the slopes of the template are plotted at a proper angle to maintain slope stability, excess or absence areas occur due to the cross-section (Figure 2). As given in Equation 1, these

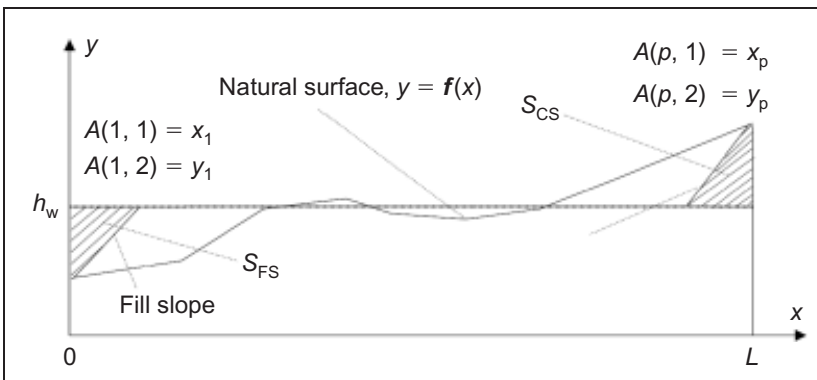

Figure I. Area correction for cut-and-fill slopes takes into account three soil properties to calculate triangular areas are subtracted for a cross-section in cut, and added for a cross-section in fill. These values are calculated at each iteration step using basic geometrical rules. It can be inferred from Equation 1 that the earthwork width must first be defined to calculate $h_{\mathrm{w}}$; however, the earthwork width of a cross-section can only be obtained after the centreline elevation of the road template is fixed. An iterative procedure (Figure 2) is applied progressively to solve this recursive problem until a predetermined confidence level $(\delta)$ is reached between successive $h_{\mathrm{w}}$ values. $^{7}$

Furthermore, Equation 2 calculates the value of $h_{\mathrm{w}}$ that balances cut-fill and minimises the sum of areas without the consideration of soil properties. Nevertheless, the excavated material will not occupy the same volume when placed in fill; therefore, the current form of the method needs to be revised. In order to achieve this, the following material properties were adopted into the WGLM by Goktepe and Lav: ${ }^{8} P_{\mathrm{S}}$ is the swelling percentage of material after excavation; $P_{\mathrm{A}}$ is the appropriateness percentage of cut material; and $P_{\mathrm{C}}$ is the compactibility percentage of fill material.

First, the excavated material swells after the excavation and this is expressed by the $P_{\mathrm{S}}$ coefficient. Similarly, excavated and swollen material is compacted by applying mechanical energy for the requirement of the engineering criteria and $P_{\mathrm{C}}$ is defined for this. Obviously, all excavated material cannot be used in a fill since some of this volume is not suitable for use as fill material. Furthermore, due to the type of material, considerable soil volume may be lost during transportation. The material property, called the appropriateness percentage $\left(P_{\mathrm{A}}\right)$ was defined to make correction for these sources of errors. It should be noted that these parameters consider volumetric changes due to explained events. Finally, the coefficient $C_{M}$ is defined to express the combined effect of all material parameters as

$$
C_{\mathrm{M}}=\frac{P_{\mathrm{A}} \times\left(1+P_{\mathrm{S}}\right)}{\left(1+P_{\mathrm{C}}\right)}
$$

The material coefficient $\left(C_{\mathrm{M}}\right)$ is a conversion parameter between the calculated cross-sectional cut and fill areas to

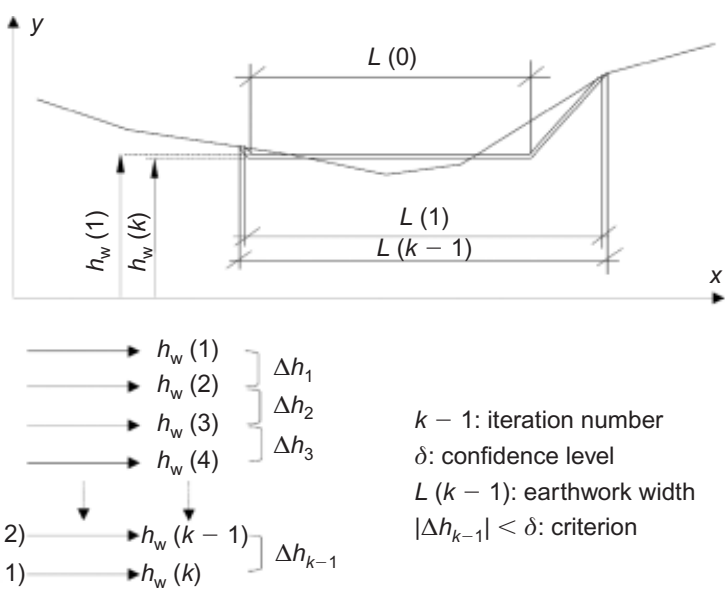

Figure 2. Iterative procedure for the calculation of earthwork width ${ }^{8}$ 
increase the precision of the WGLM. Therefore, the relationship between calculated cut and fill areas is modified by

$\sum_{i=1}^{m} S_{\mathrm{F}}(i)=C_{\mathrm{M}} \times \sum_{i=1}^{n} \boldsymbol{S}_{\mathrm{C}}(i)$

In simple words, the $C_{\mathrm{M}}$ coefficient plays an important role in characterising a correlation between calculated cut and fill areas by considering soil properties. For values of $C_{M}>1$, the cut volumes will be larger for exact (one-to-one) balancing with fill volumes; therefore, the cut areas should be decreased for proper balancing. Contrary to this, if $C_{\mathrm{M}}<1$ then the sum of fill areas should be decreased to achieve proper earthwork balance. Obviously, in the case of $C_{\mathrm{M}}=1$, there will be no need for any revision in cut or fill areas. With the definition of $\Delta H$ as the distance between $h_{\mathrm{w}}$ and $h_{\mathrm{w}}^{\prime}$ (Equation 5), the modified weighted elevation $\left(h_{\mathrm{w}}^{\prime}\right)$ makes optimum earthwork possible by $\Delta H$ shifting of the previous $h_{\mathrm{w}}$.

\begin{tabular}{|l|l|}
\hline 5 & $h_{\mathrm{w}}^{\prime}=h_{\mathrm{w}}-\Delta H$ \\
\hline
\end{tabular}

where $\Delta H$ is the amount of shifting for $y=h_{\mathrm{w}}^{\prime}$ and $h_{\mathrm{w}}^{\prime}$ is the WGE considering the material properties.

Finally, Equation 6 is given for the calculation of $\Delta \mathrm{H}$ shifting. ${ }^{8}$

\begin{tabular}{|l|l|}
\hline 6 & $\Delta H=\frac{C_{1} \times g(\Delta H)}{L(\Delta H)}$ \\
& where \\
& $C_{1}: 1-C_{\mathrm{M}}$ \\
& $g(\Delta H): \sum_{i=1}^{v} S_{\mathrm{C}}^{\prime}(i) \quad$ for $\quad y=\left(h_{\mathrm{w}}-\Delta H\right)$ \\
& $L(\Delta H): L^{\prime} \quad$ for $\quad y=\left(h_{\mathrm{w}}-\Delta H\right)$
\end{tabular}

and $S_{\mathrm{C}}^{\prime}$ is the cut areas for new positioning (for $y=h_{\mathrm{w}}^{\prime}$ ); $v$ is the number of cut areas for new positioning (for $y=h_{\mathrm{w}}^{\prime}$ ) and $L^{\prime}$ is the final earthwork width due to shifting.

This recursive function depends on the $\Delta H$ variable and the root can be found by an iterative approach, such as the method of false position and the bisection method. Details of these techniques can be found elsewhere. ${ }^{34}$ Consequently, after the calculation of $\Delta H$ using an appropriate method, the final weighted elevation $\left(h_{\mathrm{w}}^{\prime}\right)$ can be obtained by equation $5 .^{8}$

\section{FUZZY RULE-BASE SYSTEM FOR ESTIMATING THE SWELLING/SHRINKAGE FACTOR}

Basically, there are three soil properties for use with the WGLM, namely $P_{\mathrm{A}}, P_{\mathrm{S}}, P_{\mathrm{C}}$; nevertheless, it is possible to characterise two of these parameters, namely swelling and appropriateness percentages, by a unique swelling/shrinkage factor that accounts for field densities measured before excavation and after compaction. Therefore, the swelling/ shrinkage factor can be calculated with field unit weight obtained by field density measurement and maximum unit weight found by the Proctor compaction test. If the measure of the closeness of field and maximum densities is defined by a ratio, namely relative compaction $\left(C_{R}\right)$, we can define the swelling/shrinkage factor as follows ${ }^{9,35}$ where $\gamma_{\mathrm{df}}$ is field dry unit weight and $\gamma_{\mathrm{dmax}}$ denotes the maximum dry unit weight obtained by the Proctor test. Because compaction is an essential parameter indicating the structural integrity of subgrade and base layers, the $C_{R}$ parameter is a part of the compaction control procedure that is carried out throughout the road construction. Therefore, for an ongoing earthwork construction, relative compaction value depends on project specifications and the field compaction procedure. However, the $C_{R}$ parameter considered in this study is not a construction control parameter and should be measured before earthwork construction begins. The relationships between swelling/shrinkage factor $\left(F_{\mathrm{S}}\right)$ and material coefficient $\left(C_{\mathrm{M}}\right)$ is given in following expressions ${ }^{9}$

$$
8 \quad F_{\mathrm{S}}=\frac{C_{\mathrm{M}}}{P_{A}}-1=\frac{1+P_{\mathrm{S}}}{1+P_{\mathrm{C}}}-1=\left(\frac{C_{\mathrm{R}} \times \gamma_{\mathrm{dmax}}}{\gamma_{\mathrm{df}}}-1\right)
$$

$9 \quad C_{\mathrm{M}}=F_{\mathrm{S}} P_{\mathrm{A}}+1=\frac{P_{\mathrm{A}}\left(1+P_{\mathrm{S}}\right)}{1+P_{\mathrm{C}}}=\frac{P_{\mathrm{A}} C_{\mathrm{R}} \gamma_{\mathrm{dmax}}}{\gamma_{\mathrm{df}}}$

It is obvious that the $F_{\mathrm{S}}$ parameter can be calculated by Equation 8 directly using $\gamma_{\mathrm{df}}, \gamma_{\mathrm{dmax}}$, and $C_{\mathrm{R}}$ values. However, it is rational and economical to conduct a considerable number of tests before construction commences. In addition, soil behaviours are heterogeneous and isotropic, which makes it impossible to characterise them using certain expressions. Taking into consideration the ambiguity in the determination of a representative relative compaction $\left(C_{R}\right)$ value before the construction process ends, it is not appropriate to calculate an exact $F_{\mathrm{S}}$ parameter using Equation 8. As a consequence of this, it is plausible to consider existing uncertainty in the model parameters $\left(\gamma_{\mathrm{df}}, \gamma_{\mathrm{d} \text { max }}, C_{\mathrm{R}}\right.$ and $\left.F_{\mathrm{S}}\right)$ by utilising fuzzy logic and to make an approximation by fuzzy rule-based inference methodology. ${ }^{9}$

In classical sets, there are crisp boundaries, which indicate the belonging of a point to the set or not. However, in fuzzy set theory, there are uncertain territories that consider the partial belonging of the point to the set. Therefore, ambiguous information is characterised by changing the binary membership with gradual membership on the real continuous interval $[0,1]$. In this manner, fuzzy logic is a kind of multivalued logic utilising fuzzy sets to perform approximate reasoning under uncertain conditions. In fuzzy inference systems, ambiguous information is considered by means of linguistic rules as in human reasoning mechanisms. ${ }^{10-36}$

There are several inference techniques that have been developed for fuzzy systems, such as Mamdani and Assilian, ${ }^{37}$ Takagi and Sugeno, ${ }^{38}$ Tsukamoto. ${ }^{39}$ In Mamdani and Assilian's fuzzy inference system, inputs and outputs are represented by fuzzy relations in canonical form, which are associated with logical connectives. A fuzzy system involves several rules and the aggregation of these rules is as the association of fuzzy variables. Basically, there are two cases to be evaluated in the aggregation process, namely the conjunctive system of rules 
and the disjunctive system of rules. On the other hand, the Mamdani fuzzy inference technique produces a solution area instead of a singleton. For this reason, it is required to defuzzify the resulting area to a single value. The most popular defuzzification technique is the centroid defuzzification method and a defuzzified single output $\left(x^{*}\right)$ is obtained by the centroid method as follows. ${ }^{10,36,40}$

$$
x^{*}=\frac{\int \mu_{\mathrm{A}}(x) \times x \mathrm{~d} x}{\int \mu_{\mathrm{A}}(x) \mathrm{d} x}
$$

In the first phase of fuzzy model development, input variables $\left(\gamma_{\mathrm{df}}, \gamma_{\mathrm{dmax}}\right.$, and $\left.C_{\mathrm{R}}\right)$ are partitioned using triangular membership functions. In addition, input variables are associated by conjunctive (AND) connectives and fuzzy rules are aggregated with disjunctive (OR) operators. It should be noted that details of the fuzzy rule base and other characteristics of the rule base system have been published elsewhere. ${ }^{9}$ Within the content of this study, a previously developed fuzzy rule-based system was adapted into the current model.

In Figure 3, a schematic representation of the developed fuzzy rule-based system is illustrated. ${ }^{9}$ After the estimation of swelling/shrinkage factors for different road sections, the road corridor (territory limited by earthwork widths) is partitioned into several swelling/shrinkage sections with respect to calculated values. In other words, the road corridor is localised by different $F_{\mathrm{S}}$ levels that are determined by upper and lower threshold values. In Figure 4, a plan of a road corridor involving five swelling/shrinkage sections is illustrated. As can easily be derived from the figure, there are five different $F_{\mathrm{S}}$ parameters $\left(F_{\mathrm{S} 1}\right.$ to $\left.F_{\mathrm{S} 5}\right)$ to be evaluated for earthwork calculations and each section is differentiated from another with a straight line. It should be noted that these sections denote the different $F_{\mathrm{S}}$ levels that two successive regions have; nevertheless, there can be different sections having the same $F_{\mathrm{S}}$ values, which are not successive.

\section{THE ALGORITHM FOR DETERMINATION OF APPROPRIATENESS PERCENTAGE}

In this study, combining the swelling and shrinkage behaviours of fill material, we consider two soil parameters $\left(F_{\mathrm{S}}\right.$ and $\left.P_{\mathrm{A}}\right)$ for use with the WGLM. The appropriateness of cut material to properly use as a fill material (described by $P_{\mathrm{A}}$ ) requires the evaluation of several engineering properties, such as the California bearing ratio (CBR) value and maximum unit weight. The consideration of $P_{\mathrm{A}}$ is particularly important for specific conditions, such as roads constructed on weak soils, constructions made in cold regions, and existence of high liquefaction risk. The consideration of this parameter greatly depends on technical specifications, international standards and personal experiences. In this respect, the determination of this parameter belongs to the decision-maker who should also use his/her personal experience. For example, if the construction is subject to earthquake risk and the ground-water table level is high, the decision-maker may not allow the usage of the granular material due to lateral spreading or liquefaction risks.

Before the construction of earthworks, we usually have information about soil formation and geological basics. Therefore, we may locate unsuitable soil regions on the plan and make a strategy for better material hauling. In this context, we must first define certain criteria for the unsuitability (or inappropriateness) of soils. In essence, subgrade must have a certain bearing capacity in accordance with project traffic and ability to prevent excessive settlements higher than acceptable limits. Therefore, we have to use appropriate soil types to be filled and to compact them due to technical considerations, which are determined by project specifications and valid standards. Due to the technical specifications of Turkish General Directorate of Highways, the CBR must be greater than

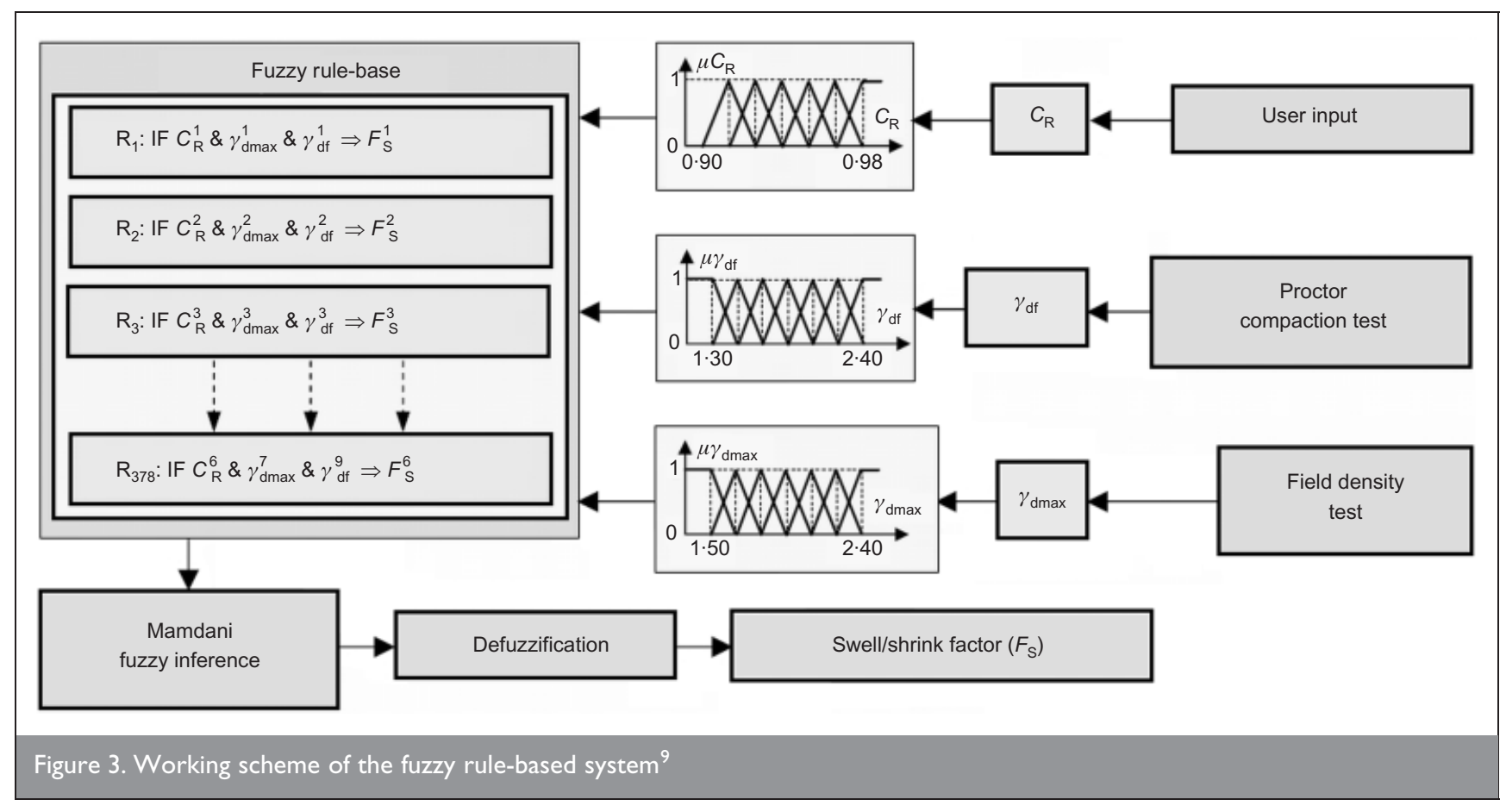




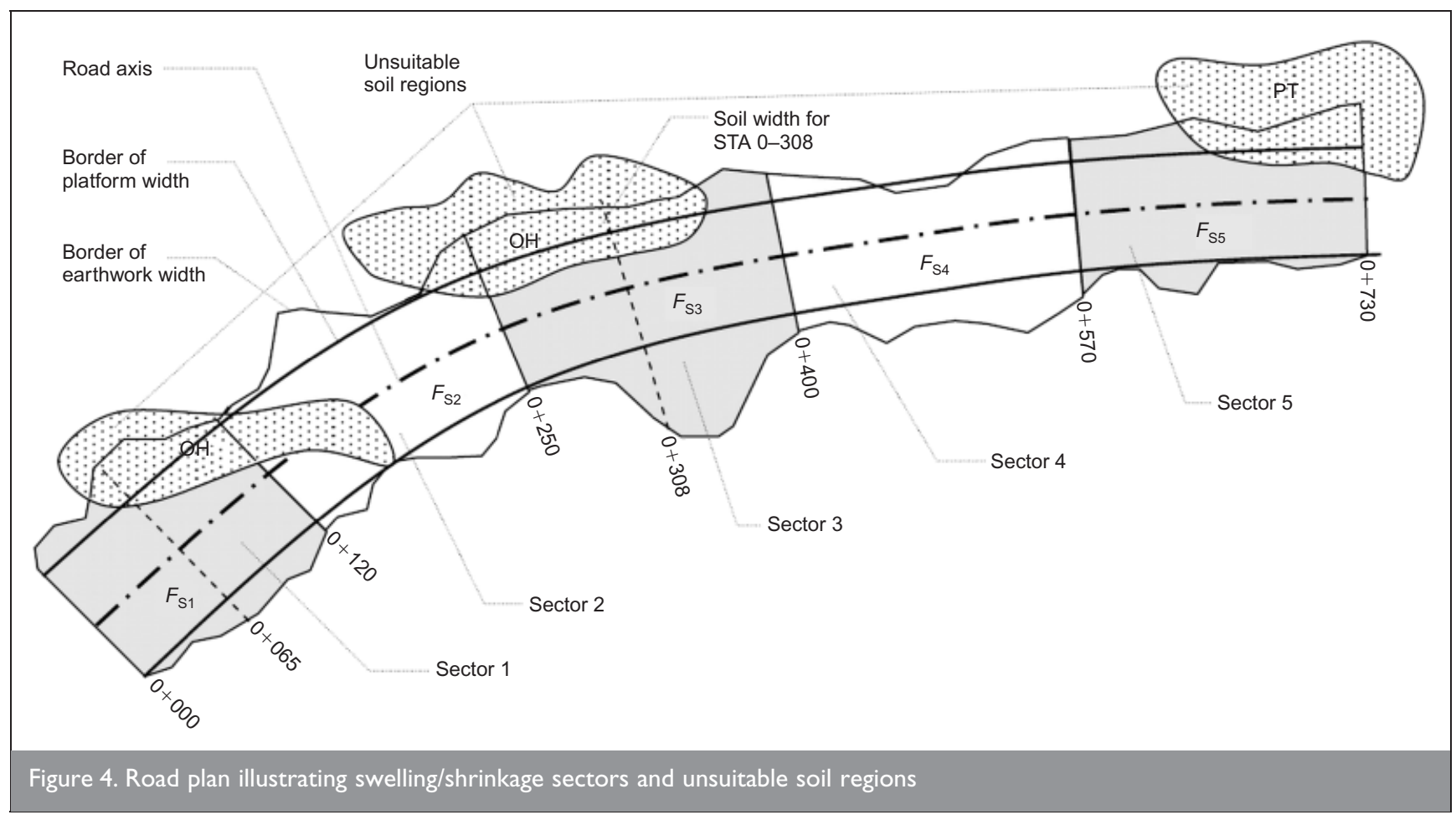

10\% and weak soils, such as topsoil, marl, rubble, organic soil and peat, are considered to be inappropriate material types. ${ }^{41}$ Within the content of this study, in accordance with the Technical Specifications of the Turkish General Directorate of Highways, ${ }^{41}$ the following criteria are determined for the appropriateness of fill materials: (a) $\gamma_{\mathrm{dmax}}>1.45 \mathrm{t} / \mathrm{m}^{3}$, (b) $\mathrm{LL}<70$, (c) PI $<40$, and (d) CBR $>10 \%$. It should be noted that the criteria could easily be changed up to different specifications involved in a highway project.

Obviously, satisfaction of the above criteria is closely related with soil classification. In Figure 4, unsuitable soil regions for a road corridor, which are indicated by $\mathrm{OH}$ (symbol of high plastic organic soil due to Unified Classification System, UCS) and PT (symbol of peat due to UCS), are illustrated. As can be seen from the figure, an unsuitable soil region may affect various chainages or stations (STAs) along the route and should be considered separately for each cross-section. Two cross-sections (STA $0+065$ and STA $0+308$ ) of the roadway are given in Figure 5. It is apparent that the $P_{\mathrm{A}}$ parameter is the ratio characterises the material suitability and can be defined by

$$
P_{\mathrm{A}}=\frac{S_{\mathrm{C}}-S_{\mathrm{U}}}{S_{\mathrm{C}}}
$$

in which $S_{\mathrm{C}}$ is the total cut area and $S_{\mathrm{U}}$ is the sum of unsuitable areas for a cross-section. Detailed explanations on the calculation of the $P_{\mathrm{A}}$ parameter can be derived from Figure 5. It should be noted that the area $S_{\mathrm{U}}$ is limited by a vertical straight line plotted due to soil width; but, this appropriateness border may not be a straight line. However, neither is it possible to know the shape of this border without drilling a bore hole, which is not economical and rational, nor whether this assumption causes a serious mistake.
After the calculation of swelling/shrinkage sections and $P_{\mathrm{A}}$ values for each cross-section, the material coefficient $\left(C_{M}\right)$ can be found from Equation 9. Successively, modified WGEs $\left(h_{\mathrm{w}}^{\prime}\right)$ are calculated utilising the WGLM methodology for each crosssection. Finally, there is one more step for the completion of the optimal vertical alignment process, in which the aim is to fit the grade line as close as possible to the modified WGEs considering the geotechnical specifications.

\section{FINAL VERTICAL ALIGNMENT WITH GA}

GA is a powerful direct searching technique utilising the theory of evolution on the basis of the 'survival of the fittest' rule. With the consideration of unique searching ability of GA for problems involving many local minima, complex constraints, and/or non-linear objective functions, it can be successfully employed in complex optimisation problems. ${ }^{42}$

Algorithmically, in the first step of GA iterations, a finite number of solution alternatives are created and the performances of the different solutions are compared with each other. In this context, decision (free) variables are first represented by genes that are in the form of binary strings. The parent solution, which is characterised by a set of genes, is referred to as a chromosome. It should be noted that the initial parent solution is determined randomly. In the successive steps of the algorithm, a new parent solution, also referred to as an offspring, is iteratively generated by means of the previous parent solution. There are three fundamental processes in GA employed to generate an offspring, namely $(a)$ reproduction, (b) crossover, (c) mutation. In the reproduction, different possible solution alternatives are created and tested with the help of the objective function's value. Next, in the crossover process, a part of the good solution is selected from the solution alternatives, and unselected choices are eliminated. Consequently, in the mutation process, the offspring are obtained. The offspring generation process is repeated until the convergence, which is defined by a stopping criterion, is 


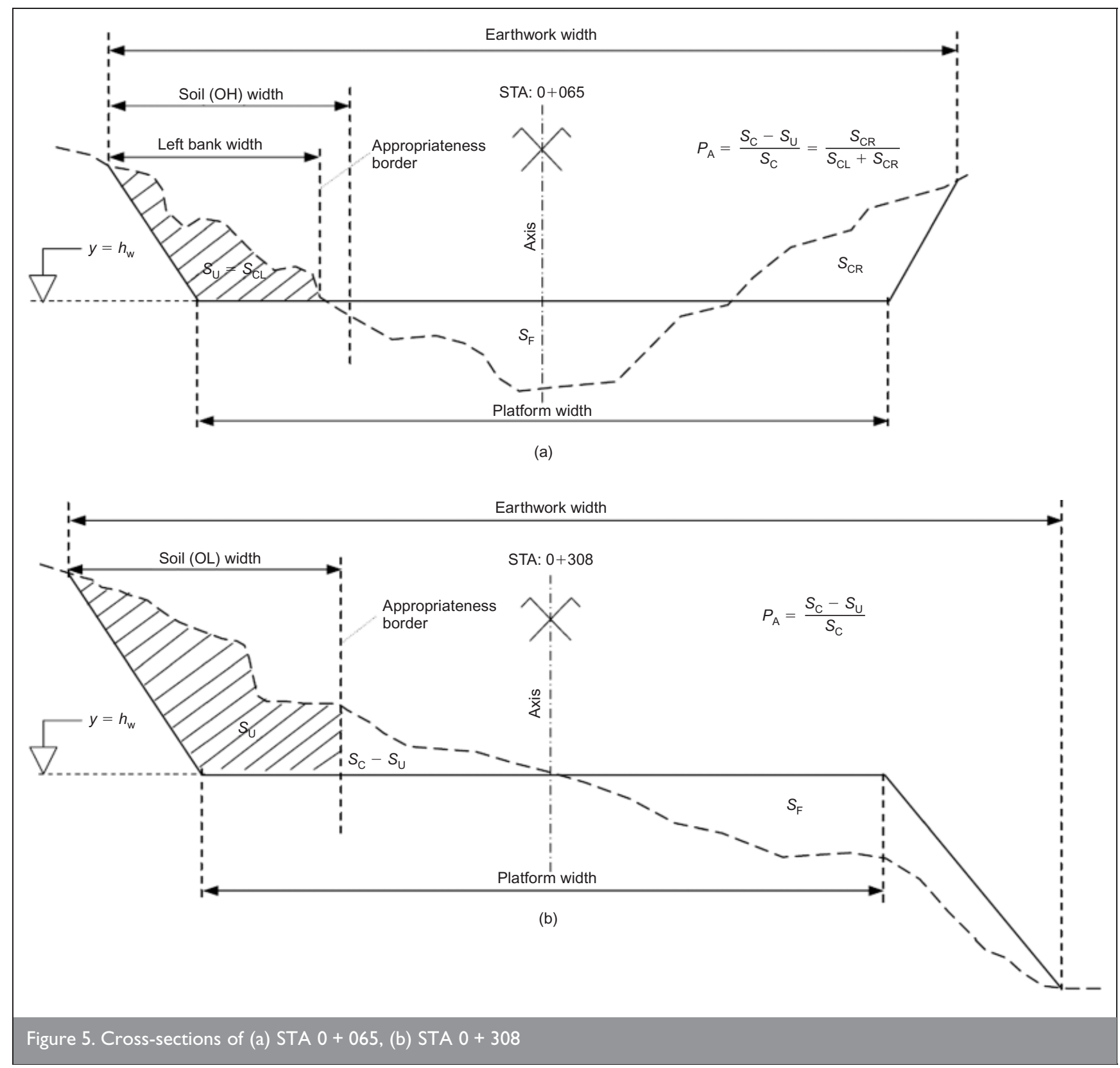

achieved by the last solution. ${ }^{3,42-44}$ A schematic representation of the GA approach is depicted in Figure 6.

In Figure 7, the weighted ground line (WGL), characterised by the hypothetical ground line and grade line are denoted by $y_{i}$ and $f_{i}$, respectively. As can be seen from the figure, $t$ is the number of stations (STAs), $d$ is the number of conjunction points (vertical curve points), $w(i, 1)$ is the $x$-coordinate of the WGE matrix, $w(i, 2)$ is the $y$-coordinate of the WGE matrix, $f(i, 1)$ is the $x$ coordinate of the grade line matrix,

$f(i, 2)$ is the $y$ coordinate of the WGE matrix, $I(j, 1)$ is the $x$ coordinate of the intersection matrix, $I(j, 2)$ is the $y$ coordinate of the intersection matrix, and $m_{i}$ denotes the slope of the tangent line. Therefore, the final vertical alignment is the combination of $d+1$ straight lines connected to each other at conjunction points, in which the free parameters are the coordinates of conjunction points. It should be noted that, after the direct search in the error space by GA, elevations of the new grade should be calculated using new conjunction points. In this context, the following piecewise expression can be used to calculate new grade elevations.

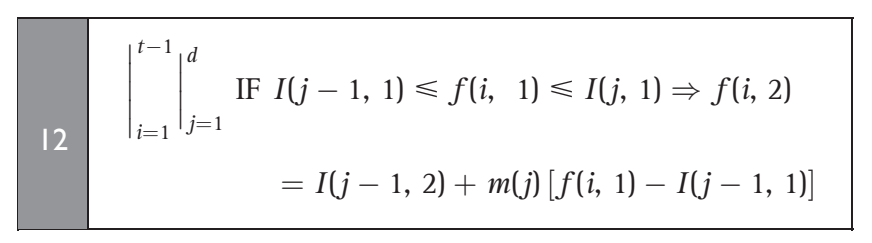

The objective function utilised in the model is based on the minimisation of sum of squared differences between calculated WGEs and grade elevations as given in Equation 13.

I3 $\quad=\min (R)\left(\begin{array}{c}\sum_{i=1}^{t}\{w(i, 2)-(I(j-1,2) \\ +[f(i, 1)-I(j-1,1)] \\ \left.\left.\times \frac{I(j, 2)-I(j-1,2)}{I(j, 1)-I(j-1,1)}\right)\right\}^{2}\end{array}\right)$




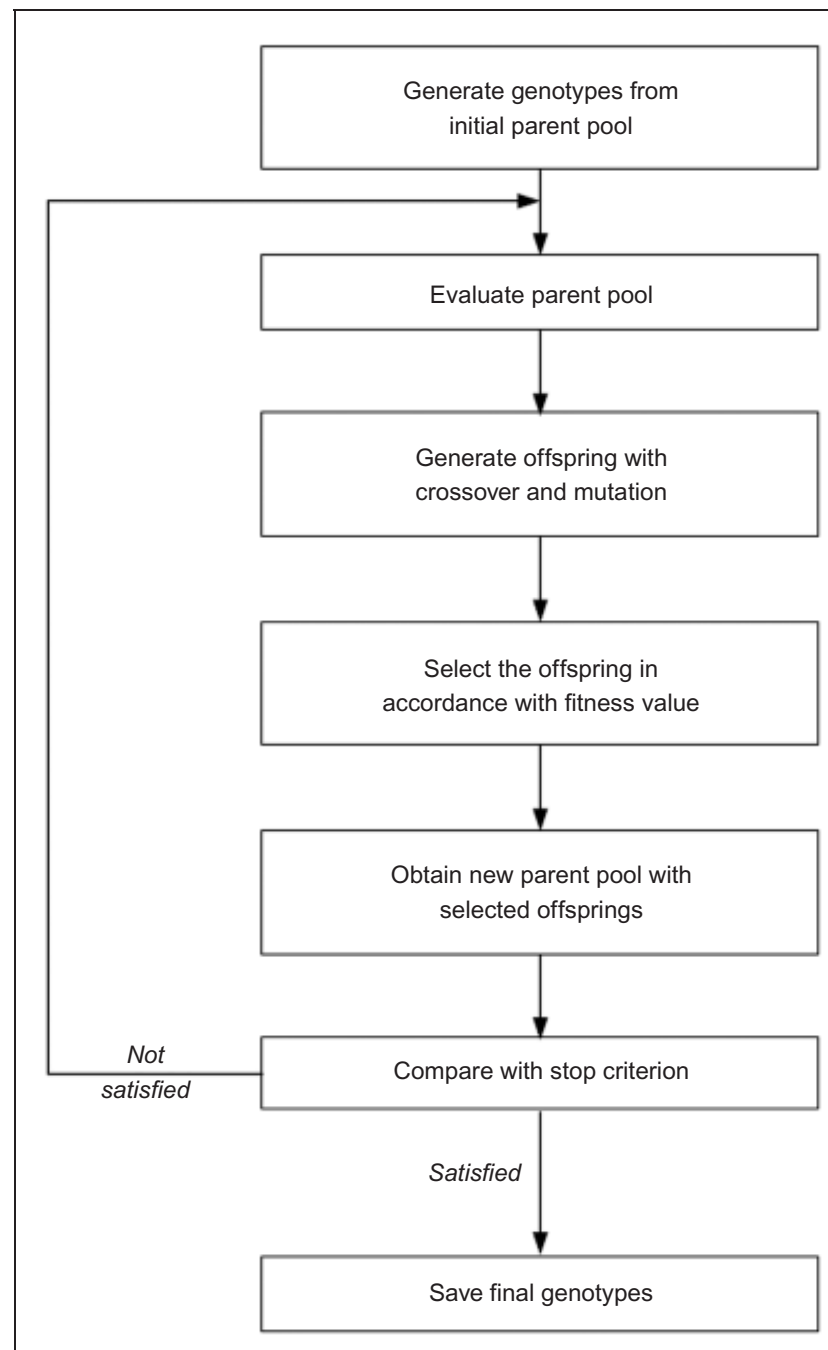

Figure 6. Flow chart of the genetic algorithm

It should be stressed for STAs on a vertical curve that Equation 13 is modified as follows

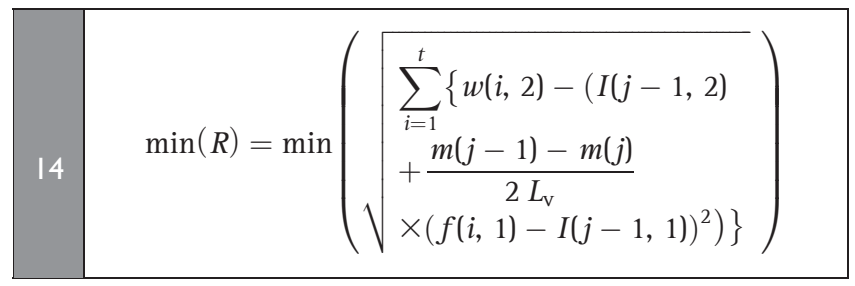

where $L_{\mathrm{v}}$ is the length of the vertical curve and $R$ denotes the error value to be minimised. Additionally, design constraints are constituted in accordance with American Association of State Highway and Transportation Officials (Aashto) 2001 design specifications. In this context, following design constraints (Equations 15 to 19) are comprised in the developed model. ${ }^{45}$

$15\left|\frac{I(j, 2)-I(j-1,2)}{I(j, 1)-I(j-1,1)}\right|=|m(j)-m(j-1)| \leqslant g_{\max }$

in which $g_{\max }$ denotes maximum allowable gradient. In addition, for crest vertical curves

\begin{tabular}{|l|l|}
\hline 16 & $g_{j} \leqslant \frac{100\left(\sqrt{2 h_{\mathrm{d}}}+\sqrt{2 h_{0}}\right)^{2}}{L_{\mathrm{v}}-2 S_{j}}$, if $L_{\mathrm{v}} \leqslant S_{j}$ \\
$g_{j} \leqslant \frac{100 L\left(\sqrt{2 h_{\mathrm{d}}}+\sqrt{2 h_{0}}\right)^{2}}{S_{j}^{2}}$, & if $L_{\mathrm{v}}>S_{j}$ \\
\hline
\end{tabular}

and for sag vertical curves

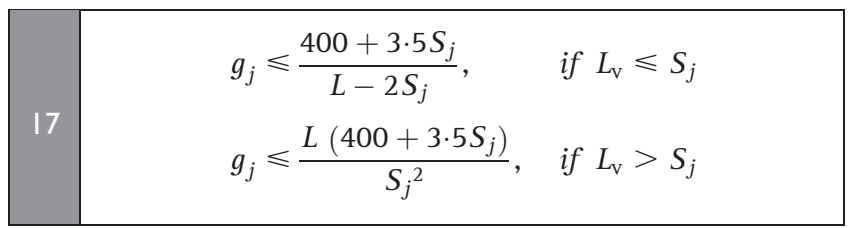

in which $h_{\mathrm{d}}$ is the height of the driver's head above the road surface, $h_{0}$ is the height of the object above the roadway surface, $S_{j}$ is the sight distance, and $g$ is the algebraic difference between successive gradients calculated with the following expression

\begin{tabular}{|l|l|}
\hline 18 & $g_{j}=m(j+1)-m(j)$ \\
& $=\frac{I(j+1,2)-I(j, 2)}{I(j+1,1)-I(j, 1)}-\frac{I(j, 2)-I(j-1,2)}{I(j, 1)-I(j-1,1)}$ \\
\hline
\end{tabular}

in which the sight distance $\left(S_{j}\right)$ is obtained by

$$
S_{j}=3 \cdot 67 V+\frac{V^{2}}{30\left(f_{r}+[I(j, 2)-I(j-1,2)]\right)}
$$

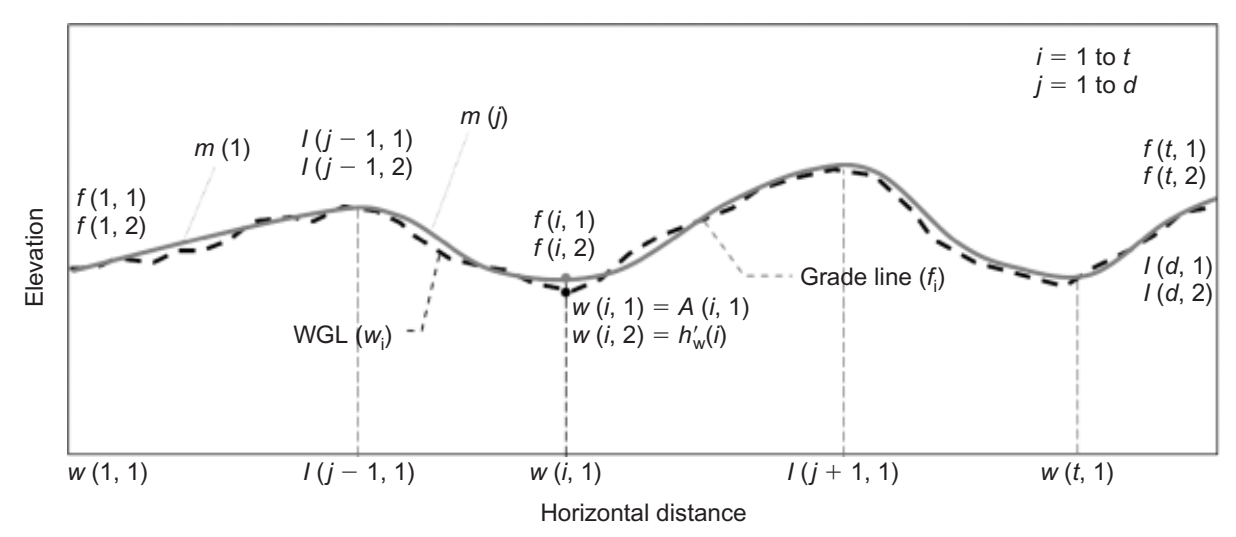




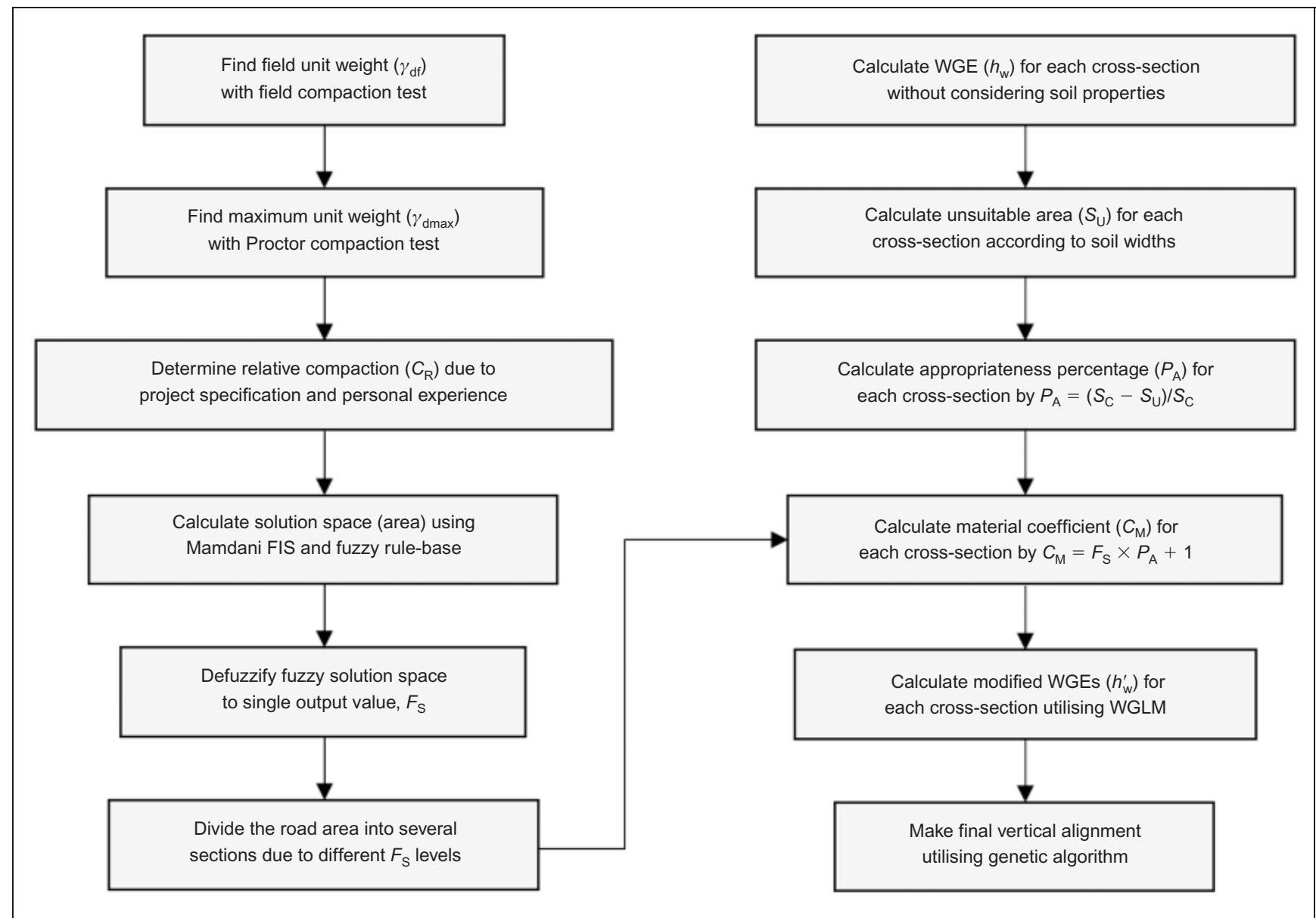

Figure 8. Developed procedure to optimise vertical alignment process

where $V$ is driving speed, and $f_{r}$ is the road friction factor.

On the other hand, in order to get a closer look at the crossover technique utilised in the genetic algorithm, let two parents characterising the current solution be defined by

20

$$
\Lambda_{i}=\left[\begin{array}{llll}
\lambda_{i} 1, & \left.\lambda_{i} 2, \ldots, \lambda_{i(2 d-1)}, \lambda_{i(2 d)}\right]
\end{array}\right.
$$$$
\text { and } \lambda_{j}=\left[\lambda_{j 1}, \lambda_{j 2}, \ldots, \lambda_{j(2 d-1)}, \lambda_{j(2 d)}\right]
$$

where $\Lambda$ is a chromosome and $\lambda$ denotes a gene. Then, the offspring obtained by the random crossover of the parents can be written as follows

2 I $\quad \Lambda_{i}^{\prime}=\left[\lambda_{i 1}, \lambda_{i 2}, \ldots, \lambda_{i(2 h-1)}, \lambda_{j(2 h)}, \ldots,, \lambda_{j(2 d-1)}, \lambda_{j(2 d)}\right]$

$22 \quad \Lambda_{j}^{\prime}=\left[\lambda_{j 1}, \lambda_{j 2}, \ldots, \lambda_{j(2 h-1)}, \lambda_{i(2 h)}, \ldots, \lambda_{i(2 d-1)}, \lambda_{i(2 d)}\right]$ where $2 h$ denotes the arbitrarily randomly generated crossover position. It should be added that the population size and the number of generations were selected as 50 and 750,

respectively. Further details on genetic algorithms and relevant procedures can be found elsewhere. ${ }^{3,43,44}$ Consequently, the illustration of the procedure developed to optimise the vertical alignment process is given in Figure 8.

\section{APPLICATION OF THE METHOD}

In order to make performance evaluation, an application of the method was made within the content of this study. Under this, the horizontal alignment was fixed and the vertical alignment was conducted using the method. The length of the roadway is $1000 \mathrm{~m}$, and the biggest difference between two WGEs was $10 \cdot 76 \mathrm{~m}(43.21 \mathrm{~m}-32 \cdot 45 \mathrm{~m})$. The lengths of the vertical curves $\left(L_{\mathrm{V}}\right)$ are 170 and $150 \mathrm{~m}$, respectively. Due to Aashto 2001 design specifications, the constraints on the GA-based optimisation procedure are given in Equations 15 to 19. It should be noted that a simple example was selected to test the performance of the method.

\begin{tabular}{|c|c|c|c|c|c|c|}
\hline STAs & & $C_{R}$ & $\gamma_{\text {dmax }}$ & $\gamma_{\mathrm{df}}$ & $F_{S}$ & $P_{\mathrm{A}}$ \\
\hline $0+000 \cdot 00$ & $-0+144 \cdot 24$ & 0.94 & $2 \cdot 25$ & 1.89 & $-12 \cdot 14$ & 0.94 \\
\hline $0+144 \cdot 24$ & $-0+360.00$ & 0.92 & 1.97 & 1.69 & -9.65 & 0.92 \\
\hline $0+360 \cdot 00$ & $-0+600 \cdot 00$ & 0.95 & $2 \cdot 34$ & $2 \cdot 14$ & $7 \cdot 58$ & 1.00 \\
\hline $0+600 \cdot 00$ & $-1+000 \cdot 00$ & 0.96 & $2 \cdot 50$ & $2 \cdot 23$ & $10 \cdot 35$ & 1.00 \\
\hline
\end{tabular}




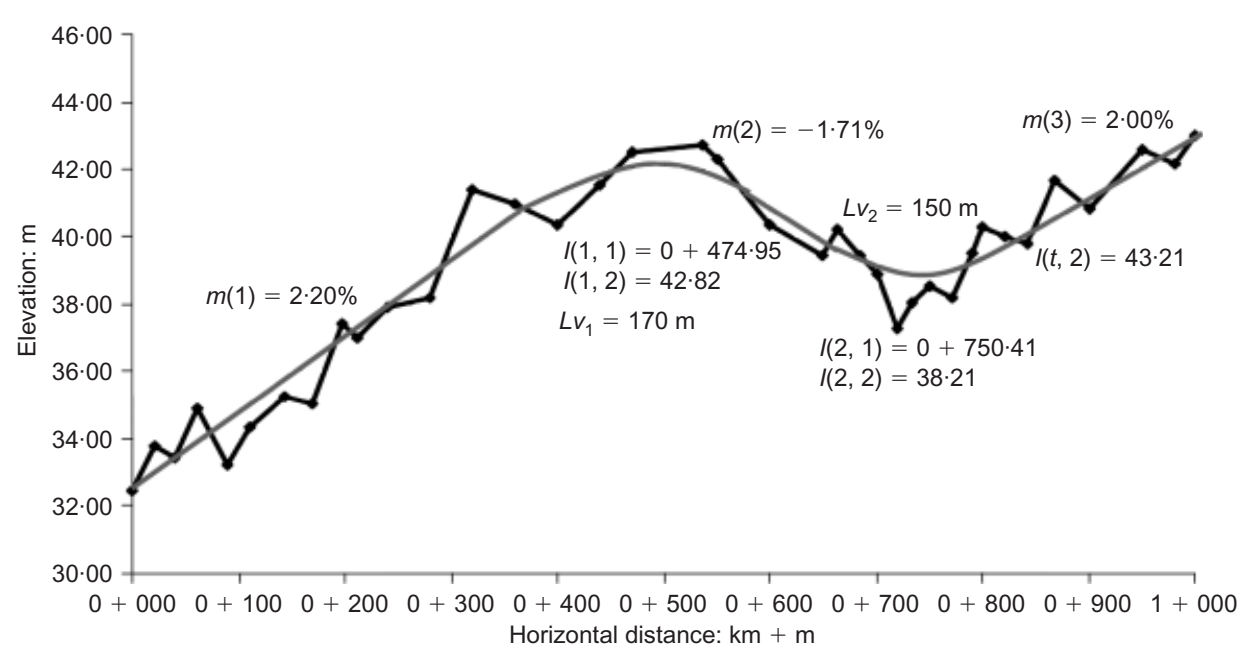

Figure 9. The profile of the vertical alignment problem

Related soil parameters were obtained using the methodologies mentioned above, and the outcomes of the fuzzy inference process as well as the appropriateness percentage algorithm, indicating the variation in soil parameters, are given Table 1. As can also be inferred from the table, there are four sectors, characterising the soil variation, on the roadway. The profile illustrating the vertical alignment is depicted in Figure 9. As can be derived from the figure, there are two intersection points at which the vertical grades change. It should be noted that five parameters were found to be appropriate for the GAbased optimisation procedure, namely the coordinates of the intersection points $(I(1,1), I(1,2), I(2,1)$, and $I(2,2))$ as well as the elevation of the destination $(\boldsymbol{f}(t, 2))$. Therefore, there are five design variables including the final elevation of the grade line, which were determined by the GA routine. It should be mentioned that the chromosomes indicated in Equations 20 to 22, which are given for even numbers characterising $x$ and $y$ coordinates, were modified for this example.

As mentioned earlier, the profile calculated by the method is given in Figure 9. As can be derived from the figure, the grade line was fitted successfully. From a numerical point of view, the error value $(R)$, which was minimised with the GA approach and given in Equation 14, was calculated as 3.73. In terms of coefficient of correlation $\left(R^{2}\right)$ value, which is the square of Pearson moment correlation coefficient, this was calculated as 0.96. Furthermore, taking account of the profile given in Figure 9 the calculated final cut and fill volumes were 9301 and $8565 \mathrm{~m}^{3}$, respectively. In order to observe the performance of the methodology objectively, Table 2 was prepared by using detailed earthwork volumes and the soil parameters (namely, swell/shrink factor and appropriateness percentage). Referring to Table 2, the calculated cut and fill volumes indicate the volumes computed from cross-sections without considering the soil parameters. Additionally, the possible fill material column includes the values indicating fill materials that could be used appropriately, and calculated by considering swelling/ shrinkage events. Namely, these values were calculated by using the procedure expressed above. As can be easily derived from the table, the next column shows the differences between fill requirements and possible fill materials obtained by the excavation. The last column, namely efficiency, shows the success of the algorithm in terms of cut-fill balancing. It should be noted that the efficiency values were calculated using the following expression Efficiency $=$ Volumetric difference/

$$
\text { [|Cut volume }|+| \text { Fill volume } \mid]
$$

where 'Volumetric difference' is the difference between the cut volume that can be utilised for fill material and the required fill volume in terms of $\mathrm{m}^{3}$. Referring to Equation 23, the reason for summing the absolute values of cut and fill volumes is to calculate the total earthwork process. Therefore, the efficiency value characterises the ratio of the material, which should be

\begin{tabular}{|c|c|c|c|c|c|c|c|c|}
\hline \multirow[t]{2}{*}{ STAs } & & \multirow[t]{2}{*}{$F_{S}$} & \multirow[t]{2}{*}{$P_{\mathrm{A}}$} & \multicolumn{2}{|c|}{ Calculated } & \multirow{2}{*}{$\begin{array}{l}\text { Possible fill } \\
\text { material: } \mathrm{m}^{3}\end{array}$} & \multirow{2}{*}{$\begin{array}{c}\text { Volume } \\
\text { difference: } \mathrm{m}^{3}\end{array}$} & \multirow[t]{2}{*}{ Efficiency: \% } \\
\hline & & & & Cut volume: $\mathrm{m}^{3}$ & $\begin{array}{l}\text { Fill volume: } \\
\mathrm{m}^{3}\end{array}$ & & & \\
\hline \multirow{5}{*}{$\begin{array}{l}0+000 \cdot 00 \\
0+144 \cdot 24 \\
0+360 \cdot 00 \\
0+600 \cdot 00\end{array}$} & $-0+144 \cdot 24$ & $-12 \cdot 14$ & 0.94 & 1950 & 1630 & 1560 & -70 & -1.96 \\
\hline & $-0+360 \cdot 00$ & -9.65 & 0.92 & 2850 & 2360 & 2295 & -65 & -1.25 \\
\hline & $-0+600 \cdot 00$ & $7 \cdot 58$ & 1.00 & 2578 & 2740 & 2773 & 33 & 0.62 \\
\hline & $-1+000 \cdot 00$ & 10.35 & 1.00 & 1835 & 1720 & 2122 & 287 & $7 \cdot 64$ \\
\hline & & & $\Sigma:$ & 9301 & 8565 & 8750 & 185 & 5.05 \\
\hline
\end{tabular}


transported by either barrowing from the pit or hauling to a storage (or fill) area, to the total earthwork movement.

Consequently, based on the results given in Table 2, the performance of the method was quite successful. If we state in detail, the results for the road section between STA $0+000$ and STA $0+600$ were outstanding. Namely, the efficiency value was less than $2 \%$. For the last section, the efficiency value was calculated as $7 \cdot 6 \%$. This value was higher than the others; nevertheless, considering the geometric constraints and topographic conditions, it can be considered to be a successful optimisation result. Additionally, the total efficiency value, which was 5\%, can also be regarded as a very successful result. It should be stated that the presented methodology not only balances cut-fill volumes but also minimises total earthwork volumes. The theoretical background of the WGLM in terms of total earthwork minimisation can be found elsewhere. ${ }^{7}$ Consequently, the total earthwork volume calculated from the example was $17866 \mathrm{~m}^{3}(9301+8565)$, which was considered to be too low for a road sector $1000 \mathrm{~m}$ in length.

\section{CONCLUSIONS}

The purpose of this study was to produce a vertical alignment method considering soil parameters, namely swelling/shrinkage factor and appropriateness percentage. Additionally, the method comprises a way of characterising the mixed crosssections, which contain both appropriate and inappropriate material in the same sector. In essence, the main contributions of this study are given below.

(a) Implementation of an innovative methodology to consider soil parameters in a roadway section. Therefore,

heterogeneous, ambiguous, and mixed (in terms of related soil parameters) roadway sections have been considered in this investigation. In this context, previously implemented fuzzy decision support methodology has been incorporated with the alignment procedure. Moreover, this paper presents a new technique to consider the appropriateness percentage in the alignment algorithm.

(b) The WGLM-based highway alignment process is completed with this paper, and the deficiencies of related optimisation process are accomplished with this study.

(c) GA is used to decide the optimum points in vertical alignment process, which was not previously applied in that manner.

(d) The GA-based vertical alignment suggestion, which focuses on the determination of conjunction points, can be an alternative to the solution of multiphase regression problems. As it is beyond the scope of this study and subject to the field of numerical analysis, no further explanations are made.

The objective function defined in this study only considers the earthwork costs; nevertheless, additional parameters, such as pavement, right-of-way and fuel consumption costs, can be adapted into the objective function with small modifications.

This paper has only dealt with soils from an earthwork optimisation perspective; nevertheless, rock material can also be used as fill material in highway projects. For this reason, another study should be performed to characterise the related material properties for rocks.
This method is not only applicable to a highway situation but is also applicable to other civil engineering disciplines involving earthwork construction.

\section{REFERENCES}

1. Jong J.-C. Optimizing Highway Alignments with Genetic Algorithms. PhD dissertation, Department of Civil and Environmental Engineering, University of Maryland, College Park, MD, USA, 1998.

2. JoNG J.-C. and SCHONFELD P. An evolutionary model for simultaneously optimizing three-dimensional highway alignments. Transportation Research Part B, 2003, 37, No. 2, 107-128.

3. Kim E., JHA K. M. and BongSoo S. A stepwise highway alignment optimization using genetic algorithms. Procedings of the 82nd Annual TRB Meeting, Washington, DC, 2003, 03-4158.

4. JHA M. K. Criteria-based support system for selecting highway alignments. Journal of Transportation Engineering, ASCE, 2003, 129, No. 1, 33-41.

5. EASA S. M. State-of-the-art of three-dimensional highway geometric design. Canadian Journal of Civil Engineering, 1997, 25, No. 3, 500-511.

6. Schoon J. G. Geometric Design Projects for Highways: an Introduction. ASCE Publication, New York, 2001, 168 pp.

7. GoKTEPE A. B. and LAV A. H. Method for optimizing earthwork considering soil properties in the geometric design of highways. Journal of Surveying Engineering, ASCE, 2004, 130, No. 4, 183-190.

8. GoKTEPE A. B. and LAV A. H. Method for balancing cut-fill and minimizing the amount of earthwork in the geometric design of highways. Journal of Transportation Engineering, ASCE, 2003, 129, No. 5, 564-571.

9. GoKtepe A. B., LaV A. H., Altun S. and Altintas G. Fuzzy decision support system to determine swell-shrink factor affecting earthwork optimization of highways. Mathematical \& Computational Applications, 2008, 13, No. 1, 61-70.

10. Ross T. J. Fuzzy Logic with Engineering Applications. McGraw Hill, New York, NY, USA, 1995.

11. Howard B. E., Bramnick Z. and ShaW J. F. B. Optimum curvature principle in highway routing. Journal of Highway Division, American Society of Civil Engineering, 1968, 94. No. 1, 61-82.

12. Athanassoulis G. C. and Calogero V. Optimal location of a new highway from A to B: a computer technique for route planning. PTRC Seminar Proceedings, Cost Models and Optimization in Highways, Session L9, PTRC, London, 1973.

13. SHAW J. F. B. and HowARD B. E. Expressway route optimization by OCP. Journal of Transportation Engineering, ASCE, 1982, 10, No. 8, 227-243.

14. TRIETSCH N. R. Comprehensive design of highway networks. Transportation Science, 1987, 21, No. 1, 26-35.

15. HAYMAn R. W. Optimization of vertical alignment for highways through mathematical programming. Highway Research Record, 1970, 306, 1-9.

16. MuRChLAND J. D. Methods of vertical profile optimization for an improvement to an existing road. PTRC Seminar Proceedings, Cost Models and Optimization in Highways, Session L12, London, 1973.

17. EASA S. M. Selection of roadway grades that minimize 
earthwork cost using linear programming. Transportation Research Part A, 1988, 22A, No. 2, 121-136.

18. GoH C. J. and CHEW E. P. Discrete and continuous models for computation of optimal vertical highway alignment. Transportation Research Part B, 1988, 22B, No. 6, 399409.

19. Chew E. P., GoH C. J. and FwA T. F. Simultaneous optimization of horizontal and vertical alignments for highways. Transportation Research Part B, 1989, 23B, No. 5, 315-329.

20. FWA T. F. Highway vertical alignment analysis by dynamic programming. Transportation Research Record, 1989, 1239, $1-9$.

21. MoReB A. M. Linear programming model for finding optimal roadway grades that minimize earthwork cost. European Journal of Operational Research, 1996, 93, No. 1, 148-154.

22. ReVelle C. S., Whitlatch E. E. and Wright J. R. Civil and Environmental Systems Engineering. Prentice Hall, Englewood Cliffs, NJ, USA, 1997.

23. FWA T. F., ChA W. T. and SiM Y. P. Optimal vertical alignment for highway design. Journal of Transportation Engineering, ASCE, 2002, 128, No. 5, 395-402.

24. Kim E., JHA K. M. and Schonfeld P. S. Intersection construction cost functions for alignment optimization. Journal of Transport Engineering, ASCE, 2004, 130, No. 2, 194-203.

25. KIM E. and JHA K. M. Intersection modeling for highway alignment optimization. Computer Aided Civil and Infrastructure Engineering, 2004, 19, No. 2, 119-129.

26. TuRner A. K. and Miles R. D. A computer-assisted method of regional route location. Highway Research Record, 1971, 348, $1-15$.

27. HoGAN J. D. Experience with OPTLOC-optimum location of highways by computer. PTRC Seminar Proceedings, Cost Models and Optimization in Highways, Session L10, PTRC, London, 1973.

28. Nicholson A. J., Elms D. G. and WillimAn A. A variational approach to optimal route location. Highway Engineers, 1976, 23, 22-25.

29. JoNG J.-C. and Schonfeld P. Optimizing vertical alignments with genetic algorithms. Proceedings of the 78th Annual TRB Meeting, Washington, DC, USA, 1999, 99-0719.

30. Hassan Y., Easa, S. M. and Abd El Halim A. 0. Design considerations for combined highway alignments. Journal of Transportation Engineering, ASCE, 1997, 123, No. 1, 60-68.

31. Kulkarni R. B., Burns R. L., Wright J., APPeR B., BAILY
T. O. and NoACK S. T. Decision analysis of alternative highway alignments. Journal of Transportation Engineering, ASCE, 1993, 119, No. 3, 317-332.

32. LEE Y. and CHENG J.-F. Optimizing grades to minimize cost and maintain traffic speed. Journal of Transport Engineering, ASCE, 2001, 127, No. 4, 303-310.

33. Sмith S. D., Wood G. S. and Gould M. A new earthworks estimating methodology. Construction Management and Economics, 2000, 18, No. 2, 219-228.

34. Chapra S. C. and CANALE R. P. Numerical Methods for Engineers. McGraw-Hill, New York, NY, USA, 1998, 924 pp.

35. Coduto D. P. Geotechnical Engineering, Principles and Practices. Prentice Hall, Englewood Cliffs, NJ, 1999, 759 pp.

36. Cox E. The Fuzzy Systems Handbook, 2nd edn. Academic Press, San Diego, CA, USA, 1999, 716 pp.

37. Mamdani E. H. and Assilian, S. An experiment in linguistic synthesis with a fuzzy logic controller. International Journal of Man-Machine Studies, 1975, 7, 1-13.

38. TAKAgI T. and SugEno M. Fuzzy identification of systems and its applications to modeling and control. IEEE Transactions on Systems, Man and Cybernetics, 1985, 15, No. 1, 116-132.

39. TSUKAмото Y. An approach to reasoning method. In Advances in Fuzzy Set Theory and Applications (GUPTA M, RAGADE R. K. and YAGER R. R. (eds)). Elsevier, Amsterdam, The Netherlands, 1979, pp. 137-149.

40. Jang R. S., Sun C. T. and Mizutani E. Neuro-fuzzy and Soft Computing. Prentice Hall, Englewood Cliffs, NJ, USA, 1997, $614 \mathrm{pp}$.

41. General Directorate of Highways (GDH). Technical Specifications for Roads. General Directorate of Highways of Turkey, Ankara, Turkey, 2001, Special Publication No. $170 / 2$.

42. FWA T. F., TAN C. Y. and CHAN W. T. Backcalculation analysis of pavement-layer moduli using genetic algorithms. Transportation Research Record, 1997, 1570, 134-142.

43. GoldBerg D. E. Genetic Algorithms in Search, Optimization and Machine Learning. Addison-Wesley, Reading, 1989.

44. Chambers L. The Practical Handbook of Genetic Algorithms. Chapman \& Hall/CRC Press, Washington, DC, USA, 2001.

45. American Association of State Highway And TransPortation OFFicials. A policy on the geometric design of highways. In Highway Design Manual. AASHTO, Washington, DC, 2001.

\section{What do you think?}

To comment on this paper, please email up to 500 words to the editor at journals@ice.org.uk

Proceedings journals rely entirely on contributions sent in by civil engineers and related professionals, academics and students. Papers should be 2000-5000 words long, with adequate illustrations and references. Please visit www.thomastelford.com/journals for author guidelines and further details. 